\title{
Efficacy and Safety of Imidapril in Patients with Essential Hypertension: A Double-Blind Comparison with Captopril
}

\author{
Por-Jau Huang Kou-Liong Chien Ming-Fong Chen Ling-Ping Lai \\ Fu-Tien Chiang \\ Department of Internal Medicine (Cardiology Division), National Taiwan University Hospital, Taipei, Taiwan
}

\section{Key Words}

Imidapril · Hypertension - Captopril •

Angiotensin-converting enzyme inhibitor

\begin{abstract}
In this 12-week, double-blind, parallel-group, comparative trial, 57 adult patients with mild-to-moderate hypertension were randomly allocated to receive imidapril or captopril, initially at a dose of $5 \mathrm{mg}$ once a day and $25 \mathrm{mg}$ twice daily, respectively. After 4 weeks of therapy, the dose of each drug was increased twice if diastolic blood pressure (DBP) remained $\geq 90 \mathrm{~mm} \mathrm{Hg}$. Both treatments effectively lowered DBP in a comparable manner. Mean changes from baseline in DBP at 12 weeks were $-9.9 \mathrm{~mm}$ $\mathrm{Hg}$ for imidapril and $-8.8 \mathrm{~mm} \mathrm{Hg}$ for captopril ( $p=0.488$ ). Responder rates in patients receiving active treatment for at least 6 weeks were $53.9 \%$ for imidapril and $48 \%$ for captopril ( $p=0.676$ ). Both treatments were well tolerated. Adverse drug reactions were observed in $20.7 \%$ (6/29) of the imidapril group and $46.4 \%$ (13/28) of the captopril group $(p<0.05)$. A cough was the most frequent side effect, reported in $13.8 \%$ of the imidapril group and $35.7 \%$ of the captopril group. The results indicate that imidapril is as effective as captopril in the treatment of hypertension. Imidapril produces less adverse effects compared with captopril.
\end{abstract}

Copyright $(2001$ S. Karger AG, Basel

\section{KARGER}

Fax +41613061234

E-Mail karger@karger.ch

www. karger.com
(C) 2001 S. Karger AG, Basel

0008-6312/01/0953-0146\$17.50/0

Accessible online at:

www. karger.com/journals/crd

\section{Introduction}

Angiotensin-converting enzyme (ACE) inhibitors have been established as one of the first choice of the antihypertensive drugs $[1,2]$. They are also effective in retarding the progression of diabetic nephropathy [3] and in reducing mortality in heart failure [4]. Although ACE inhibitors are usually well tolerated, a dry persistent cough with the incidence ranging from 1 to $33 \%[5,6]$ is an annoying problem that occasionally necessitates a withdrawal of the drug.

Imidapril is a novel ACE inhibitor without the sulfhydryl group, currently under investigation for treatment of hypertension [7-9] and heart failure [10, 11]. It is a prodrug that is converted by the liver to its active metabolite, imidaprilat. It has been reported that $5-10 \mathrm{mg}$ of imidapril once a day effectively decreases blood pressure in essential hypertensives [7-9]. Interestingly, the drug may have a relatively low incidence of cough $[8,9,12]$. Saruta et al. [8] observed that imidapril had a lower incidence $(0.9 \%)$ of cough than that of enalapril $(7 \%)$. Recently, in a multicenter, double-blind, cross-over study, Saruta et al. [9] also found that $52.8 \%$ of the patients with an enalaprilassociated cough did not develop a cough after switching to imidapril, while all of the patients with an imidaprilassociated cough developed a cough after switching to enalapril. In contrast, Shionoiri et al. [13] observed that $98.3 \%$ of the patients with an ACE inhibitor-induced
Por-Jau Huang, MD

Department of Internal Medicine (Cardiology Division)

National Taiwan University Hospital

No. 7, Chuang-Shan South Road, Taipei 10016 (Taiwan)

Tel. +886 2 23123456, ext. 5031, Fax +8862 23957855, E-Mail porjau@ha.mc.ntu.edu.tw 
cough developed cough-related symptoms after receiving imidapril. They stressed that imidapril is not different from other ACE inhibitors in inducing a cough.

In Chinese patients receiving ACE inhibitors, an even higher incidence of cough has been observed than in Caucasians [14]. The aim of the present study was to perform a randomized, double-blind study to evaluate the efficacy and cough incidence of imidapril, compared with captopril, in the treatment of mild to moderate hypertension in Chinese patients.

\section{Patients and Methods}

\section{Patients}

Male and female outpatients with mild to moderate essential hypertension ranging in age from 30 to 70 years were eligible to participate in this study. Mild to moderate hypertension was defined as sitting diastolic blood pressure (DBP) ranging from 95 to $115 \mathrm{~mm} \mathrm{Hg}$ on two occasions ( 1 week apart) during a placebo run-in period of 2 or 3 weeks. Important exclusion criteria included the presence of heart failure, a history of myocardial infarction in the preceding 3 months, pregnancy, poorly controlled diabetes, angina pectoris, second- or third-degree heart block, significant hepatic or renal disease and secondary hypertension. All patients gave written consent to participate in the study. The study protocol was approved by the Institutional Review Board of the National Taiwan University Hospital and by the Taiwan Government (the Department of Health, Taiwan). The trial was conducted according to Good Clinical Practice requirements.

\section{Study Design}

This study was a randomized, double-blind, parallel-group and dose titration trial. The design included a placebo run-in period of 2 or 3 weeks and an active treatment period of 12 weeks. After a singleblind, double-dummy, placebo run-in period, patients who met the inclusion criteria were randomly assigned to receive either $5 \mathrm{mg}$ imidapril daily or $25 \mathrm{mg}$ captopril twice daily. The double-blind, doubledummy treatment period consisted of a 4-week titration phase followed by an 8-week maintenance phase. Imidapril, its placebo and captopril were put into completely identical capsules. Patients on the imidapril regimen received a capsule (containing $5 \mathrm{mg}$ imidapril) in the morning and a placebo capsule in the evening. Patients on the captopril regimen received a capsule (containing $25 \mathrm{mg}$ captopril) each morning and evening. After 4 weeks of therapy, the dose of each drug was increased twice if sitting DBP was still $\geq 90 \mathrm{~mm} \mathrm{Hg}$. Concomitant medications with antihypertensive properties were prohibited throughout the duration of the trial.

Patients were assessed at baseline and every 2 weeks during the treatment period. At each visit, pulse rate, sitting systolic blood pressure (SBP) and DBP and adverse events were recorded. For each patient, blood pressure was measured on the same arm and by the same physician. Blood pressure was measured twice at 5-min intervals after the patient had rested in a sitting position for $10 \mathrm{~min}$, using a mercury sphygmomanometer. The average of the 2 measurements was taken for evaluation. Measurements were carried out at each visit at the same time of the morning before daily dosing. Therefore, for imidapril, blood pressure was measured 22-26 $\mathrm{h}$ after the intake of the prior morning dose. Korotkoff phase $\mathrm{V}$ was used for the measurement of DBP. The 12-lead electrocardiogram and body weight were recorded at the beginning and at the end of the trial. Patient compliance was estimated by a pill count at each visit to the clinic.

\section{Efficacy Assessment}

The primary efficacy variable was the change from baseline in the mean sitting DBP at the endpoint of therapy. Secondary efficacy variables included the change in mean sitting SBP from baseline and responder rates (defined as the percentage of patients at the endpoint with sitting DBP $<90 \mathrm{~mm} \mathrm{Hg}$ or decrease in DBP $\geq 10 \mathrm{~mm} \mathrm{Hg}$ compared to baseline).

\section{Safety Assessment}

Routine hematological, biochemical and urinary parameters were measured during the run-in period, at 4 weeks and at 12 weeks. The hematology measurements included hemoglobin, hematocrit, white blood count, differential cell count and platelet count. The blood chemistry examinations included total bilirubin, alkaline phosphatase, blood urea nitrogen, serum transferase, creatinine, serum sodium, potassium, chloride, total cholesterol and glucose. The urinalysis included sediment and dipstick urinalysis for protein, blood and glucose.

All adverse events reported by the patient or observed by the investigator were recorded according to their duration, severity and relation to study treatment. The latter two were graded on a threepoint scale. Any adverse event was reported in detail on the Case Report Form. A dry cough without identifiable cause lasting for more than 1 week and of sufficient severity was regarded as test druginduced, whereas a cough which accompanied sneezing and/or a sore throat and ceased after treatment with medication was not considered as drug-induced.

\section{Statistical Analysis}

Two data sets were used for data analysis. The 'intent-to-treat' data set included all patients who took at least one treatment dose and had baseline data. The 'per-protocol' population included all patients who received active treatment for at least 6 weeks.

For comparison of differences between the two treatment groups, an unpaired t test was utilized. $\chi^{2}$ test or Fisher's exact test was applied for the categorical variables. The changes in blood pressure and heart rate from the baseline were compared between the treatment groups by using the analysis of covariance with each baseline value as a covariate. The changes from baseline of blood pressure, heart rate and laboratory parameters in each medication group were assessed by paired $t$ test. Differences were considered as statistically significant if $\mathrm{p}<0.05$.

\section{Results}

\section{Patient Disposition and Baseline Demographics}

A total of 57 patients were allocated randomly to imidapril $(n=29)$ and captopril $(n=28)$. All of these patients were qualified as the intent-to-treat population. There were no significant differences between the two treatment groups with respect to baseline demographic data (ta- 
Table 1. Baseline demographic characteristics

\begin{tabular}{lcc}
\hline & $\begin{array}{l}\text { Imidapril } \\
(\mathrm{n}=29)\end{array}$ & $\begin{array}{l}\text { Captopril } \\
(\mathrm{n}=28)\end{array}$ \\
\hline Males & $14(48)$ & $17(61)$ \\
Females & $15(52)$ & $11(39)$ \\
Age, years & $52.4 \pm 6.9$ & $52.5 \pm 7.1$ \\
Weight, kg & $65.4 \pm 10.6$ & $67.9 \pm 10.5$ \\
\hline Hypertension duration & & \\
Newly diagnosed & $2(7)$ & $2(7)$ \\
$\quad$ 5 5 years & $16(55)$ & $19(68)$ \\
$\quad$ 5-10 years & $8(28)$ & $3(11)$ \\
SBP, mm Hg & $3(10)$ & $4(14)$ \\
DBP, mm Hg & $152.2 \pm 15.5$ & $149.1 \pm 14.0$ \\
Pulse rate, beats/min & $99.2 \pm 4.4$ & $99.0 \pm 3.4$ \\
\hline
\end{tabular}

Values are expressed as means \pm SD. Figures in parentheses represent percentage. No significant differences were found between groups.

Table 2. Sitting DBP and SBP (intent-to-treat data set)

\begin{tabular}{rrrllr}
\hline & \multicolumn{2}{l}{$\mathrm{DBP}, \mathrm{mm} \mathrm{Hg}$} & & \multicolumn{2}{l}{$\mathrm{SBP}, \mathrm{mm} \mathrm{Hg}$} \\
\cline { 2 - 3 } \cline { 6 - 6 } & $\begin{array}{l}\text { imidapril } \\
(\mathrm{n}=29)\end{array}$ & $\begin{array}{l}\text { captopril } \\
(\mathrm{n}=28)\end{array}$ & & $\begin{array}{l}\text { imidapril } \\
(\mathrm{n}=29)\end{array}$ & \multicolumn{1}{l}{$\begin{array}{l}\text { captopril } \\
(\mathrm{n}=28)\end{array}$} \\
\hline Baseline & $99.2 \pm 0.8$ & $99.0 \pm 0.6$ & & $152.2 \pm 2.9$ & $149.1 \pm 2.6$ \\
2 weeks & $-5.0 \pm 1.5$ & $-4.0 \pm 1.2$ & & $-10.9 \pm 2.3$ & $-7.7 \pm 1.8$ \\
4 weeks & $-7.4 \pm 1.5$ & $-6.4 \pm 1.2$ & & $-13.4 \pm 2.1$ & $-7.8 \pm 1.9$ \\
6 weeks & $-9.5 \pm 1.3$ & $-5.7 \pm 1.7$ & & $-16.8 \pm 2.2$ & $-8.6 \pm 3.1$ \\
8 weeks & $-11.0 \pm 1.3$ & $-7.6 \pm 1.5$ & & $-18.6 \pm 2.3$ & $-12.3 \pm 2.9$ \\
10 weeks & $-10.3 \pm 1.5$ & $-8.5 \pm 1.5$ & & $-18.7 \pm 2.2$ & $-11.5 \pm 3.0$ \\
12 weeks & $-9.9 \pm 1.3$ & $-8.8 \pm 1.5$ & & $-19.0 \pm 2.2$ & $-12.8 \pm 2.8$ \\
\hline
\end{tabular}

Values are means \pm SEM.

ble 1). Fifty-one of the 57 patients receiving medications $\geq 6$ weeks were classified as the per-protocol population. The remaining 6 patients, 3 in each group, received treatment for less than 6 weeks. Of the 6 patients, 2 in each group discontinued the treatment because of side effects. The other 2 patients (one in each group) withdrew because there was no therapeutic effect.

\section{Antihypertensive Efficacy}

Table 2 shows serial changes in the blood pressure measured at 2-week intervals. Both the imidapril and cap-
Table 3. Adverse drug reactions

\begin{tabular}{lll}
\hline & $\begin{array}{l}\text { Imidapril } \\
(\mathrm{n}=29)\end{array}$ & $\begin{array}{l}\text { Captopril } \\
(\mathrm{n}=28)\end{array}$ \\
\hline Coughing & $4(13.8)$ & $10(35.7)$ \\
Impotence & $1(3.4)$ & 0 \\
Dysgeusia & $1(3.4)$ & $2(7.1)$ \\
Pruritus & 0 & $1(3.6)$ \\
Diarrhea & 0 & $1(3.6)$ \\
Proteinuria & $1(3.4)$ & 0 \\
Abnormal liver function & 0 & $1(3.6)$ \\
Total number of patients with ADR & $6(20.7)$ & $13(46.4)^{*}$ \\
\hline
\end{tabular}

Figures in parentheses represent percentage. One of 6 patients taking imidapril and 2 of 13 patients taking captopril had more than one adverse drug reaction (ADR). $* p<0.05$ vs. imidapril.

topril treatments were effective at lowering sitting DBP and SBP. The reduction from baseline for either group was statistically significant after 2 weeks of treatment $(\mathrm{p}<$ 0.05 ), and the effect persisted throughout the treatment period. Before week 8, there was a tendency toward a greater reduction in DBP and SBP as the treatment period lengthened. There was no statistically significant difference between the two groups at any measurement point. After 12 weeks of monotherapy, mean changes from baseline in DBP were $-9.9 \mathrm{~mm} \mathrm{Hg}$ for imidapril and $-8.8 \mathrm{~mm}$ $\mathrm{Hg}$ for captopril $(\mathrm{p}=0.488)$. Mean changes from baseline in SBP were -19.0 and $-12.8 \mathrm{~mm} \mathrm{Hg}$ for imidapril and captopril, respectively $(p=0.065)$. There were no significant changes of the mean heart rate from baseline at each visit in either treatment group.

In the intent-to-treat population, the responder rate was $48.3 \%$ in the imidapril group and $46.4 \%$ in the captopril group $(p=0.889)$. In the per-protocol population, the responder rate was $53.9 \%$ in patients taking imidapril and $48 \%$ in those taking captopril $(\mathrm{p}=0.676)$. The normalized rate (defined as the percentage of patients with DBP $<90 \mathrm{~mm} \mathrm{Hg}$ ) was $46.2 \%$ in the imidapril group and $40 \%$ in the captopril group $(p=0.657)$.

\section{Safety}

Twenty-two (75.9\%) patients in the imidapril group and $24(85.7 \%)$ patients in the captopril group reported one or more adverse events at some point during the 12week double-blind, comparative treatment period. Of these, only $6(20.7 \%)$ patients in the imidapril group and $13(46.4 \%)$ patients in the captopril group ( $p<0.05$ vs. imidapril) suffered adverse events that were considered 
by the investigator to be related to the trial medication (table 3). In both treatment regimens, the most frequently reported side effect was a dry cough. The incidence of drug-related coughing was more than twice as high with captopril (35.7\%) than with imidapril (13.8\%). Statistically the difference was of borderline significance $(\mathrm{p}=$ 0.055).

One patient receiving imidapril had mild proteinuria. Another patient taking captopril had mild elevation of levels of aminotransferases. The remaining patients in either group did not have relevant changes in laboratory parameters during the study. There were no serious adverse experiences reported in this trial.

\section{Discussion}

Imidapril is a long-acting ACE inhibitor. The elimination half-life was $2 \mathrm{~h}$ for imidapril and $8 \mathrm{~h}$ for imidaprilat [15]. ACE activity was still suppressed to under $40 \%$ of the baseline value $24 \mathrm{~h}$ after 5- and 10-mg doses [7]. In patients with mild to moderate hypertension, 5-10 mg once daily of imidapril was judged as effective in $71 \%$ of treated patients [8]. High doses did not significantly increase the response rate [7]. Captopril, on the other hand, is the first ACE inhibitor. In the treatment of mild to moderate hypertension, 50-100 $\mathrm{mg}$ per day was found effective [2, 16]. A starting dose of $25 \mathrm{mg}$ twice a day seems appropriate for most patients [16]. Therefore, the doses and the frequency of dosing selected in the present double-blind study were 5-10 mg once daily for imidapril and 25-50 mg twice per day for captopril.

Results of this study show that imidapril 5-10 mg once a day is at least as effective as captopril 25-50 mg twice daily in reducing blood pressure in patients with mild to moderate hypertension. There are no significant differences in antihypertensive efficacy between the two agents. The reductions in DBP and SBP by imidapril and captopril are of a similar magnitude. In the present study, the normalized rate (DBP $<90 \mathrm{~mm} \mathrm{Hg}$ ) in the per-protocol population was $46.2 \%$ for imidapril and $40 \%$ for captopril. This is consistent with the study by Saruta et al. [8] who reported that the normalized rate was $40.7 \%$ for imidapril and $40 \%$ for enalapril.

The present study also assessed the safety of the two drugs. We found that both trial medications were well tolerated during the treatment period. However, adverse drug reactions occurred less commonly in patients taking imidapril than in those taking captopril (20.7 vs. $46.4 \%$, $\mathrm{p}<0.05)$.

Imidapril versus Captopril
The fact that there are fewer side effects, especially coughing, in the imidapril group compared with captopril is of interest. Woo et al. [14] reported that Chinese patients had a very high incidence of cough associated with ACE inhibitors. Using a quality-of-life questionnaire, they observed that the prevalence of cough was $54 \%$ in Chinese patients receiving captopril for $16 \pm 5$ months compared with 19\% in Caucasians receiving captopril for a similar period of time. In this study coughing occurred in $35.7 \%$ of patients taking captopril for 12 weeks. The high incidence of a captopril-induced cough in Chinese in the present study is comparable with the results of Woo et al. However, a cough occurred only in $13.8 \%$ of the cohort taking imidapril. The relatively low incidence of cough in patients with imidapril has also been observed among Japanese patients [8, 9, 12]. Saruta et al. [8] reported that a cough occurred in $0.9 \%(1 / 108)$ of patients treated with imidapril for 12 weeks compared with $7 \%$ (8/115) with enalapril. In a multicenter study [9], the incidence of cough was reported to be significantly lower in the imidapril group (15.2\%) than in the enalapril group $(38.6 \%)$.

The exact mechanism of an ACE inhibitor-induced cough remains unclear. Several mechanisms have been proposed [17-23]. Bradykinin, which is normally inactivated in part by ACE, accumulates in the lung as a result of inhibition of ACE. Accumulation of bradykinin stimulates afferent vagal $\mathrm{C}$ fibers [18] and enhances bronchoconstriction [19], thus promoting a cough. Substance P, a potent bronchoconstrictor, is also degraded by ACE. Therapy with ACE inhibitors could result in local accumulation of this substance, leading to a cough in susceptible patients [20]. Both bradykinin and substance P augment formation of prostaglandins, which may be involved in the pathogenesis of a cough [21, 22].

Sasaguri et al. [24] in an in vitro study using purified canine lung ACE disclosed that different ACE inhibitors had different potencies in the hydrolysis of bradykinin and angiotensin I. Their data showed that the accumulation of bradykinin relative to the inhibition of angiotensin II formation was significantly reduced with imidaprilat than with enalaprilat, ramiprilat or captopril. This may partly explain the relatively low incidence of cough for imidapril, as noted in the present study as well as other clinical trials.

Cardiology 2001;95:146-150 


\section{Conclusions}

This study shows that imidapril $5-10 \mathrm{mg}$ once a day is at least as effective as captopril $25-50 \mathrm{mg}$ twice daily in reducing blood pressure. Both drugs were generally well tolerated. However, imidapril produced fewer side effects compared with captopril. Thus, imidapril can be prescribed effectively and safely in patients with mild to moderate hypertension.

\section{Acknowledgment}

This study was partly supported by Taiwan Tanabe Seiyaku Co., Ltd., Taipei.

\section{References}

1 Guidelines Subcommittee: 1999 World Health Organization-International Society of Hypertension guidelines for the management of hypertension. J Hypertens 1999; 17:151-183.

2 Joint National Committee: The sixth report of the Joint National Committee on prevention, detection, evaluation and treatment of high blood pressure. Arch Intern Med 1997;157: 2413-2446.

3 Lewis EJ, Hunsicker LG, Bain RP, Rohde RD, for the Collaborative Study Group: The effect of angiotensin-converting enzyme inhibition on diabetic nephropathy: The Collaborative Study Group. N Engl J Med 1993;329:14561462

4 Garg R, Yusuf S, for the Collaborative Group on ACE Inhibitor Trials: Overview of randomized trials of angiotensin-converting enzyme inhibitors on mortality and morbidity in patients with heart failure. JAMA 1995;273: 1450-1456.

5 Israili ZH, Hall WD: Cough and angioneurotic edema associated with angiotensin-converting enzyme inhibitor therapy: A review of the literature and pathophysiology. Ann Intern Med 1992;117:234-242.

6 Karlberg BE: Cough and inhibition of the renin-angiotensin system. J Hypertens 1993; 11(suppl 3):S49-S52.

7 Vandenburg MJ, Mackay EM, Dews I, Pullan T, Brugier S: Dose-finding studies with imidapril: A new ACE inhibitor. Br J Clin Pharmacol 1994;37:265-272.

8 Saruta T, Omae T, Kuramochi M, Iimura O, Yoshinaga $\mathrm{K}$, Abe $\mathrm{K}$, Ishii $\mathrm{M}$, Watanabe $\mathrm{T}$, Takeda T, Ito K, Kokubu T, Fujishima M, Arakawa K, Nakajima M: Imidapril hydrochloride in essential hypertension: A double-blind comparative study using enalapril maleate as a control. J Hypertens 1995;13(suppl 3):S23-S30.
9 Saruta T, Arakawa K, Iimura O, Abe K, Matsuoka H, Nakano T, Nakagawa M, Ogihara T, Kajiyama G, Hiwada K, Fujishima M, Nakashima M: A multicenter comparative study of imidapril and enalapril on usefulness and incidence of cough. J New Remedies Clin 1998;47: 249-282.

10 Pinto YM, van Veldhuisen DJ, Tjon-Ka-Jie RT, Rooks G, Netzer T, Lie KI: Dose-finding study of imidapril, a novel angiotensin converting enzyme inhibitor, in patients with stable chronic heart failure. Eur J Clin Pharmacol 1996;50:265-268.

11 Van Veldhuisen DJ, Genth-Zotz S, Brouwer J, Boomsma F, Netzer T, Man in't Veld AJ, Pinto YM, Lie KI, Crijns HJGM: High-versus lowdose ACE inhibition in chronic heart failure: A double-bind, placebo-controlled study of imidapril. J Am Coll Cardiol 1998;32:1811-1818.

12 Nishikawa Y, Ogawa S: Incidence of cough induced by imidapril in patients with hypertension with enalapril-associated cough. Curr Ther Res 1997:58:601-608.

13 Shionoiri H, Takasaki I, Minainisawa K, Ueda S, Kihara M, Shindo K, Hiroto S, Sugimoto K, Himeno H, Naruse M, Nagamochi I, Yasuda G: Cough-challenge trial with a new angiotensin-converting enzyme inhibitor, imidapril. J Clin Pharmacol 1998;38:442-446.

14 Woo KS, Norris RM, Nicholls G: Racial difference in incidence of cough with angiotensinconverting enzyme inhibitors (a tale of two cities). Am J Cardiol 1995;75:967-968.

15 Hirota Y, Kawamura K, Ooyagi A, Hayashi S, Morioka A, Terasaki Y, Tagawa K, Mizobe M: Phase I study of TA-6366 (I): Single oral administration. Rinshou Iyaku 1992;8:507-522.
16 Kaplan NM: Angiotensin-converting enzyme inhibitors; in Kaplan NM (ed): Clinical Hypertension, ed 6. Baltimore, Williams \& Wilkins, 1994, pp 240-246.

17 Bucknall CE, Neilly JB, Carter R, Stevenson $\mathrm{RD}$, Semple PF: Bronchial hyperreactivity in patients who cough after receiving angiotensin converting enyzme inhibitors. Br Med J 1988; 296:86-88.

18 Kaufman MP, Coleridge HM, Coleridge JCG, Baker DG: Baker DG: Bradykinin stimulates afferent vagal C-fibers in intrapulmonary airways of dogs. J Appl Physiol 1980;48:511517.

19 Fuller RW, Dixon CM, Cuss FM, Barnes PJ: Bradykinin-induced bronchoconstriction in humans: Mode of action. Am Rev Respir Dis 1987;135:176-180.

20 Shore SA, Stimler-Gerard NP, Coats SR, Draz en JM: Substance P-induced bronchoconstriction in the guinea pig: Enhancement by inhibitors of neutral metalloendopeptidase and angiotensin-converting enzyme. Am Rev Respir Dis 1988; 137:331-336.

21 Hartung HP, Heininger K, Schafer B, Toyka $\mathrm{KV}$ : Substance $\mathrm{P}$ and astrocytes: Stimulation of the cyclooxygenase pathway of arachidonic acid metabolism. FASEB J 1988;2:48-51.

22 Coleridge HM, Coleridge JC, Ginzel KH, Baker GD, Banzett RB, Morrison MA: Stimulation of 'irritant' receptors and afferent C-fibres in the lungs by prostaglandins. Nature 1976;264: 451-453.

23 Yeo WW, Ramsay LE, Morice AH: ACE inhibitor cough: A genetic link? Lancet 1991;337: 187.

24 Sasaguri M, Ideishi M, Kinoshita A, Arakawa $\mathrm{K}$ : Differential inhibition of bradykinin hydrolysis by four ACE inhibitors: A possible explanation for differences in induced coughing. Hypertens Res 1994;17:253-258. 
Copyright: S. Karger AG, Basel 2001. Reproduced with the permission of S. Karger AG, Basel. Further reproduction or distribution (electronic or otherwise) is prohibited without permission from the copyright holder. 